\title{
Pyelonephritis Lenta
}

\section{Consideration of Childhood Urinary Infection as the Forerunner of Renal Insufficiency in Later Life}

\author{
MALCOLM MACGREGOR \\ From the Children's Unit, Warwick Hospital, Warwick
}

The great cascade of medical articles about urinary infection at every age, which has marked the past decade, shows signs now of slackening. It is time to take stock. Among children it is realized how commonly urinary infection is accompanied by radiographic alterations of the kidney with a tendency to recurrences, and this has led to a minatory and at times to a sepulchral view of their future. This review attempts to find an answer to the question 'what happens to children with scarred kidneys when they grow up?'. In order to do this several separate strands of inquiry have been followed, and the data derived from studies of morbid anatomy, of $x$-ray investigations, of clinical reports, and of statistics, have been woven together in the attempt to arrive at conclusions.

\section{Uncertainty of Pathological Diagnosis}

Black (1966) defines chronic pyelonephritis as, 'established and progressive damage to kidneys, initiated and probably perpetuated by infection of the urinary tract'. In this definition one detects a note of caution, and Black admits that the central problem in chronic pyelonephritis is to know when the patient has got it, for the changes held to be characteristic may be mimicked by other diseases. Weiss and Parker (1939), whose criteria for the diagnosis based on the study of 100 necropsies were long classical, themselves remarked that in the healing stages diagnosis could only be established with a fair degree of probability. A recent review of necropsies in a Connecticut hospital between 1957 and 1964 (Freedman, 1967) showed a progressive decline in frequency of the pathological diagnosis of chronic pyelonephritis, from $2 \cdot 4 \%$ of necropsies in $1957-59$, to $0.6 \%$ in $1962-64$. This decline, greater in men than in women, is considered to be due to a growing appreciation of the non-specificity of the pathological features of chronic pyelonephritis. Freedman does not consider that morphological criteria are specific enough to separate the agency of bacterial infection from that of hypertension, toxaemia of pregnancy, hereditary changes, and nephrotoxins, unless there is sufficient confirmatory clinical and bacteriological evidence. Angell, Relman, and Robbins (1968) confirm that the histological picture, long described as chronic non-obstructive pyelonephritis, is one of the commonest associations with renal failure, but not all cases are clearly associated with bacterial infection. The appearances are often designated as 'chronic active pyelonephritis' when polymorphs abound in the tissue. Angell et al. closely compared 20 kidneys of this kind, obtained either at operations or at necropsy from patients aged 21 to 65 , with their clinical case records, and in 12 of them no evidence could be found to support urinary infections at any time. Moreover the renal disease was observed to progress without coincident infection of the urine. Because pyelonephritis of the type labelled 'chronic active' comprises less than half of the total, their conclusion is that in a high proportion of kidneys labelled as chronic pyelonephritis there is no clinical support for infection. Kimmelstiel et al. (1961) found it necessary to refine the pathological diagnosis of chronic pyelonephritis by the use of histological criteria so severe that $50 \%$ of scarred kidneys were excluded, observing also that a history of acute pyelonephritis is said to be rare in advanced cases of this kind, in which inflammation appears to advance independently of continuing bacterial infection. Halverstadt, Leadbetter, and Field 
(1966) performed biopsies upon 80 kidneys of juvenile diabetics with retinopathy, and detected 7 cases of chronic pyelonephritis by Kimmelstiel's criteria, but only one of them had bacteriuria, and one other a positive direct culture from the biopsy specimen. They too conclude that factors other than the presence of bacteria in the kidney may play a role in the pathogenesis of chronic pyelonephritis. Relman (1966) summarizes the situation as follows: 'The commonest histological finding in patients with chronic progressive renal insufficiency is a diffuse inflammatory lesion easily distinguished from glomerulo-nephritis and most other common renal diseases, which is called chronic pyelonephritis, without necessarily implying that it is specifically and solely the result of bacterial infection.'

These many observations, all tending to deny to urinary infection a primary or even a dominant role in causation of the commonest sort of renal destruction to be seen in adult necropsies, indicate the need for great caution in ascribing any part of this to childhood occurrences.

\section{Two Types of Pyelonephritic Kidney}

It has been repeatedly pointed out that there are two forms of diseased kidney labelled as chronic pyelonephritis, namely, the classical irregularly contracted type, and also a diffuse, evenly contracted type in which the kidneys are smaller (Kincaid-Smith, McMichael, and Murphy, 1958; Rosenheim, 1963). Now the first variety, chronic focal or atrophic pyelonephritis, is well established as the consequence of serious infection in early life (Longcope and Winkenwerder, 1933). Indeed Hodson (1965a), whose views are based on radiological study, considers that with rare exceptions the small irregularly shrunken kidney with large renal scars only results from infection in childhood, and that destruction of the renal pyramids adjacent to the scars is an invariable and diagnostic accompaniment. The condition has been discovered to develop rapidly over a period of 1 to 2 years, and Hodson believes that its onset is always within the first decade of life. In a very high proportion of cases it is found in company with vesico-ureteric reflux. It is a major cause of uraemia in young adult life, and is closely associated with hypertension and sometimes with osteodystrophy. It is an entity distinguishable from other forms of chronic pyelonephritis. Rosenheim (1963), writing as a clinician, agrees with Hodson's concept of chronic focal pyelonephritis, and points out that pathologists have seldom mentioned atrophy of the renal pyramids and calyceal dilatation as a criterion of chronic pyelonephritis, whereas these are regarded as essential features of the disease by radiologists. $\frac{\rho}{\overline{\frac{D}{0}}}$ Accordingly, Smith (1962) decided to inquire into the usefulness at necropsy of the criterion of atrophy $\overrightarrow{\vec{D}}$ of the renal papilla in relation to cortical scars, in preference to conventional criteria (dilated tubules $\frac{\overline{0}}{0}$ with colloid casts, vascular changes, and interstitial $\overline{\frac{\bar{\sigma}}{\sigma}}$. cellular infiltration) upon which pathologists are $\underset{\varrho}{\stackrel{0}{\varrho}}$ accustomed to rely. He studied 37 kidneys from patients in which circumstantial evidence provided ${ }^{\infty}$ a clear differentiation between a vascular and an $\vec{O}$ infective cause. He found that papillary atrophy $\overrightarrow{\vec{\omega}}$ was unobtrusive and had to be sought for carefully, $\omega_{\infty}$ but in only 1 of 23 ischaemic kidneys was it present, and in only 1 of 14 infective cases was it absent. (The papillary atrophy under consideration is of distinct both by $x$-rays and at necropsy from the sclerotic type of renal papillary necrosis of the? middle aged, commonly found with a history of $\vec{c}$ diabetes or of analgesic abuse, and carrying a bad prognosis.) In adult hypertensives, however, Hick- $\frac{}{5}$ ler et al. (1965) found that in one-third of cases the $\vec{\longrightarrow}$ $x$-ray criteria of clubbed calyces and thinned $\frac{D}{2}$ cortex in a contracted kidney were not alone sufficient to distinguish renal artery stenosis from $\vec{\theta}$ unilateral pyelonephritis as the cause of symptoms. Little, McPherson, and De Wardener (1965) carried out pyelograms on 20 adults at the time of an attack of acute pyelonephritis, and again up to 2 years later. In 12 cases there was an over-all shrinkage of the kidney (sometimes on both sides) which they interpreted as the result of cortical $\stackrel{2}{\Rightarrow}$ destruction. They suggest that in adults, unlike $\frac{0}{3}$ children, chronic pyelonephritis causes destruction $\frac{3}{\sigma}$ of the renal parenchyma without localized scarring, calyceal clubbing, or distortion. Williams (1965) also suggests that chronic pyelonephritis with onset? in adult life leads to small kidneys rather than to scarred ones. Hodson and Wilson (1965) observe 3 . that the highest incidence of focal renal scarring is seen between 10 and 15 years, and decreases $₹$ thereafter up to 45 , and that whereas in children $\mathrm{O}$ scarring tends to be progressive, in adults it often? remains unchanged. Similarly, De Wardenero (1965) finds $x$-rays not of much use in following up adult cases of pyelonephritis, as it is then unusual o to detect new scars or fresh clubbing.

There is, then, fairly general agreement that chronic focal pyelonephritis is predominantly an ${ }_{\sigma}$ entity of young people and seldom arises later in life.

\section{Generally Contracted Kidney}

On the other hand, the small, evenly contracted kidney 'remains one of the enigmas of medicine', to quote Rosenheim (1963), especially in younger $\stackrel{\mathbb{Q}}{\stackrel{\mathbb{Q}}{2}}$ 
people. Among 100 necropsy examples of 'pyelonephritic' kidneys, Weiss and Parker (1939) described a group aged less than 30 who had died in uraemia, nearly all with hypertension and with very small kidneys. None of these was hypoplastic in the sense of normal but small, and Weiss and Parker considered that such small kidneys represented solely the effects of infection dating from childhood. Platt and Davson (1950) found 5 cases of 'bilateral renal hypoplasia' among 188 examples of severe renal disease. These patients were all renal dwarfs aged 18 to 25 in chronic uraemia. The nature of the pathology the authors found impossible to determine. Emmett, Alvarez-Ierena, and McDonald (1952) reviewed 183 cases of unilateral atrophic kidney seen at the Mayo Clinic. Two-thirds were in women, and the commonest ages were between 21 to 50 , though a few were younger. It was considered impossible to distinguish between acquired and congenital factors in aetiology, whether on clinical, pathological, or radiological grounds. By modern standards, however, the radiographic assessment would be considered inadequate. Kanasawa et al. (1965) distinguished two groups among 11 children who had been labelled on $x$-ray criteria as suffering from bilateral renal hypoplasia. In 6 there was present a slowly progressive non-bacterial inflammatory disease of the renal parenchyma, chronic glomerulonephritis at necropsy. In the other 5, clinically identical, there were gross malformations, with dysplasia principally affecting the collecting system. Secondary pyelonephritis was also present. This second group is suggestive of the entities recently described as juvenile nephrophthisis and medullary cystic kidney, which may indeed be the same condition with two names (Mongeau and Worthen, 1967). In these states, destructive cystic malformations of the distal tubule and loop of Henle lead to death before the age of 40 , with symptoms of anaemia, polyuria, azotaemia, and osteodystrophy. Spicer et al. (1969) describe characteristic urographic changes in renal medullary cystic disease, enabling diagnosis in childhood during life. This condition is a member of the group of so-called 'hereditary nephritis' to which scant attention has been paid, and yet which must always be considered in attempts to evaluate the meaning of small kidneys in young people. Perkoff (1967) indicates that several of these entities are sex-linked, with increased severity in males, and suggests that the $\mathrm{X}$ chromosome may have importance in the development of the kidneys, and even speculates whether this fact may have a bearing on the increasing male contribution to pyelonephritic deaths in later life.
Whalen and McIntosh (1962) list the hereditary nephritides as follows:

Lowe's oculo-cerebro-renal dystrophy.

Alport's hereditary nephritis, with or without auditory or ocular defects.

Juvenile nephrophthisis, and medullary cystic kidney.

Familial dysplasia of kidneys, liver, and pancreas.

The nail-patella syndrome, Fabry's disease, and familial hyperprolinaemia.

These conditions are importantly represented within the no-man's land of small contracted kidneys causing juvenile renal failure, though some entities are less easily confused with chronic pyelonephritis than others. The haemolyticuraemic syndrome, also, is recognized to give rise to severe subsequent lesions in survivors, which may be wrongly attributed. Gianantonio et al. (1968) found that $20 \%$ of survivors had progressive renal disease and $10 \%$ had died 8 years later with progressive nephrosclerosis. Brentjens et al. (1968) showed in rabbits that a wide range of severe renal changes, some closely resembling chronic pyelonephritis, was caused by diffuse intravascular clotting, which underlies the haemolytic-uraemic syndrome in man. And there are probably other entities as yet undefined that contribute to end-state nephrosclerosis in the young.

We must conclude that to use the label chronic pyelonephritis with any certainty, one requires at any age strong corroborative evidence from clinical records, and even so the possibility of alternative diagnoses must be remembered.

\section{Influence of Vesico-ureteric Reflux}

It is now necessary to consider in a general way the relation of vesico-ureteric reflux to destructive renal infection at various ages. There is unassailable evidence from many sources that the presence of reflux renders a child with recurrent infection liable to progressive renal damage (Williams, 1965). For example, Lloyd Still and Cottom (1967), who investigated 18 hypertensive children whose symptoms were thought to depend on uncomplicated pyelonephritis, found reflux in all the 9 patients in whom it was looked for. The incidence of reflux in children with recurrent non-obstructive urinary infection is estimated at from 30 to $50 \%$ (Stamey, Govan, and Palmer, 1965; Smellie and Normand, 1966). Nearly all children with focal pyelonephritic scarring in $x$-rays also show reflux, and the onset of scarring in such cases is usually in the first decade and very often within the first 5 years of life (Hodson, 1965b; MacGregor and Freeman, 1968). Hutch, Ayres, and Noll (1967) point out that the 
incidence of reflux in children in published cases diminishes inversely with the severity of pyelonephritis, from $85 \%$ of those with focally scarred kidneys, $45 \%$ of those with recurrent infections, down to $5 \%$ of those studied for enuresis. Baker et al. (1966) likewise noted a steady decline of reflux with age among 798 patients with urinary abnormalities, from $26 \%$ in younger age-groups to $5 \cdot 2 \%$ in adults. $80 \%$ of children with reflux seemed to have lost it by adult life. Death or operation certainly did not account for all these, and in many infection was continuing, so the majority must have restored themselves to normal. Smellie (1966) noted that half of a series of infected children had lost reflux after 1 to 9 years of conservative treatment, and other authors record the same happening (Turner-Warwick, 1962; Penn and Breidahl, 1967; Blight and O'Shaughnessy, 1969). Williams (1965) has noticed that even major reflux may cease when chronic pyelonephritis is well established; therefore, when adult patients with typical focal scarring fail to show reflux, it has probably ceased. Renal scarring is associated with all grades of reflux, however, and not merely with the most severe (Smellie, 1966), and its damaging effects seem to be due to the access of bacteria to the kidney which its presence allows, and not to mechanical backpressure on renal arteries (Ashken, 1967). Nevertheless, a special vulnerability to the damaging effects of reflux with infection must exist in the very young child, as discussed by MacGregor and Freeman (1968). It seems probable that reflux in unobstructed renal tracts should be looked upon as a congenital defect with a tendency to cease with increasing age (Spence et al., 1964; Hinman and Miller, 1964; Bruezière, 1965), a concept that is supported by a familial tendency to reflux, and a not uncommon association with renal malformation in sibs (MacGregor and Freeman, 1968). Except perhaps in the newborn (Laplane and Etienne, 1968), the concept of reflux as a temporary accompaniment of acute urinary infection (Hanley, 1964), at any rate in children, is losing ground.

Although, as we have stated, reflux may have ceased by adult life, it is being found with increased frequency to underlie severe pyelonephritic symptoms in adults, when it is sought for. Thus, Williams et al. (1968) found reflux in $21 \%$ of bacteriuric post-partum women aged 18 to 28,10 of whom also had focal pyelonephritic scarring. Klotz (1969) describes 8 patients aged 20 to 43 who were found to have reflux in association with urinary infections that had apparently originated after the age of 20, but as 5 of them had focal pyelonephritic scarring, inapparent infection had presumably antedated detection. Kern and Malament (1969) consider that any patient under 45 with pyelonephritis should be examined for reflux, and theyes consider that in adult life the condition has passed 6 the stage of possible spontaneous regression $\frac{\mathrm{C}}{\mathrm{O}}$ McGovern and Marshall (1969) describe 35 adults with pyelonephritis and reflux, who were discoveredo either because of hypertension or because of infection, and conclude that most had had reflux ${ }^{\text {s }}$ all their lives, and that it was the primary reason for infection. They suspect that a long asymptomatic phase after infected reflux in childhood may be not infrequent sequence in patients with apparentlyo idiopathic pyelonephritis in adulthood, and, simi-n larly, with pyelitis of pregnancy. That reflux cantr exist uninfected for long periods without embarrass - N ment to renal function is stressed by Kase $(1965)$. who quotes a patient of 37 , with a 23 -year history $\vec{G}$ of bilateral reflux and no loss of renal function.0 This illustrates that it is reflux plus infection that is damaging, and it seems that the earlier the infec $-\overrightarrow{-}$ tion, the worse potentially is the damage.

In early life the presence of infection is often unrecognized. Thus, Meadow, White, and John- $\overrightarrow{0}$ ston (1969) found 2 unsuspected cases of infectedo reflux by routine urine screening of 1026 apparently healthy schoolgirls, while Savage et al. (1969) whos tested 943 5-year-old schoolgirls for bacteriuria, detected by this means 8 with infected reflux, 3 on whom already had focal renal scarring on $x$-ray In none of these children had the parents recog nized that anything was wrong, and in later life these patients would have been unaware of having had a urinary infection in early childhood. Screen-F ing the urines of children still younger, we havefound in Infant Welfare Clinics in South Warwick shire 3 cases of urinary infection, 2 with gross reflux among 200 symptomless children aged between 13 and 2 years. ${ }^{\star}$ The earlier reflux is discovered the better are the opportunities for protecting the kidneys from its results, but screening methodso at present are unfortunately indirect and mus? wait upon the arrival of infection.

Perhaps, therefore, if greater attention were paid to two points, namely, to the search for reflux aso an essential inquiry in the investigation of alh patients suspected of pyelonephritis, and to then criterion of papillary atrophy in post-mortem ${ }_{-}^{\omega}$ diagnosis of pyelonephritis, greater clarity would result.

We must now consider more directly the consequences of urinary infection in childhood upono

* This work was supported by a grant from the Research? Committee of the Birmingham Hospital Board. 
patients who have reached adult life. For this purpose we must consider information from three sources, from published follow-up surveys of urinary infections, from accounts of necropsy findings in renal disease, and from statistical sources. Each of these will be examined in turn.

\section{Follow-up Surveys}

As Bergström et al. (1968) observe, many controversial opinions have arisen from the use of heterogeneous material in these surveys. Everybody knows that obstructive uropathy, gross renal malformation, and neurogenic defects affecting the urinary system have a bad prognosis, and we intend here to leave these groups (which amount to about a quarter of urinary infections in children seen in hospital (MacGregor and Freeman, 1968)) out of consideration as far as is possible. Unfortunately, in many surveys such cases are inseparable from the rest, and prognoses based upon them are therefore of little worth. A comprehensive general survey of the literature has recently been provided by Smallpeice (1968).

Unselective surveys of children. Wharton, Gray, and Guild (1937) described a 13-year followup of 30 hospital paediatric cases of acute or recurrent urinary infection. Just over half had 'urinary abnormalities' and these are not specified. Even so, the general health of nearly all was good when re-examined at ages of 8 to 27 , and only one had progressed to renal insufficiency, though many were still infected. The authors considered their group unrepresentative of urinary infections in general, as it contained many of the worst cases. Woodruff and Everett (1954) discuss 76 children, all of whom had urinary infection before 1949, and were reexamined later after a minimum of 5 years had elapsed. The oldest at re-examination was 32 years. There had not been much investigation in the first attack, but at follow-up 39 were found to have a 'urological abnormality'. Nevertheless, nearly all were in good health and only one had hypertension, though there had been a pronounced liability to pyelitis of pregnancy among them. Steele, Leadbetter, and Crawford (1963) described the follow-up of 72 unselected cases of urinary infections in children, first seen between 1940-50, and aged 11 to 27 at the time of re-examination. Among those with onset under 2 years old, there had been a high mortality; 13 were dead, and the majority of these were boys. In 6 other patients there had been a deterioration in $x$-ray appearances or in renal function ('chronic advancing disease'), but these patients were all included in the $35 \%$ who had congenital malformation or outflow obstruction. Continuing urinary infection without decrease in renal function was observed in $27 \%$ while the remaining $63 \%$ were well and uninfected. The incidence of toxaemia of pregnancy was unusually high. Macaulay (1964) reviewed 200 children admitted to hospital for urinary infection, and found that among the 32 patients with persistent or recurrent infection all the 12 boys had structural abnormalities, whereas the 20 girls had apparently normal urinary tracts. Murdoch et al. (1966) emphasized, however, that $33 \%$ of 1281 females of all ages admitted to their unit for urinary infection between 1960 and 1964 had some renal scarring. In a long-term follow-up of 350 childhood cases of infection, Stansfeld (1966) found that the 6 deaths all occurred in the group with gross congenital malformations. Laplane and Etienne (1968) considered the outcome of neonatal infection, in a review of 34 cases of their own and a survey of 227 published cases. $X$-ray changes had been present in a minority, for malformations seldom seem to get infected within 2 months of birth. The literature gave no hint of the ultimate fate of these children, but 27 of their own cases had been followed up for more than a year with only 2 relapses and no deterioration. The view that uncomplicated neonatal infection is seldom attended with sequels after recovery is also held by MacGregor and Freeman (1968).

The general import of the studies so far described is that fatal infections occur in the group of children with severe congenital malformations, which consists largely of males, and such deaths occur within the first 2 years of life, but not in the neonatal period. During subsequent childhood and early adult life most of the rest stay largely symptomless and in good health, though subject to reinfection, notably during pregancy, and frequently possessed of pyelographic abnormality. Hypertension and evidence of decrease in renal function is seen only occasionally.

Unselected surveys of adults. Longcope and Winkenwerder (1933), in an article that sharply focuses the problem central to this inquiry, declare that if one has an opportunity to watch many children through adolescence to middle life, he may remember the rare instance of a child with persistent pyelitis who died when a young adult in uraemia'. Such patients are mainly young women who die from contracted kidneys, in terminal uraemia with hypertension. 'In some instances a history of pyelitis in childhood is obtained.' The authors described 9 such fatal cases, all women, 4 
dying between 15 and 20, 4 between 20 and 30, and one at 36 years of age. 'It is remarkable', they wrote, 'to what extent the insufficiency of renal function may advance in these patients without noticeable impairment in health of the individual.'

Hanley (1964) reviewed 67 women who had had acute pyelonephritis 17 to 25 years previously. No less than $43 \%$ were found to have serious renal disease at follow-up 'as a result', Hanley writes, 'of acute pyelonephritis previously'. But this is an unusual group in whom 12 were hypertensive, and among whom calculi, non-functioning kidney, and nephrectomies figure in the history, suggesting that much of the trouble must be attributed to congenital or surgical uropathies of earlier date.

Bengtsson, Lincoln, and Hood (1967) studied a group of adults with chronic pyelonephritis (average age 43) for decrease in renal function over a period of observation while on treatment. They found that most cases preserved their renal function unaltered. Improvement was rare, and advancing deterioration was likely if renal papillary necrosis was present, or if the renal function was already less than $50 \%$ at the beginning of the study.

McGovern and Marshall (1969) detected 35 adults with chronic pyelonephritis and reflux during an investigation of hypertension and of recurrent urinary infection. Over $60 \%$ had a history of childhood infection, and in the others they suspected that the childhood phase had been asymptomatic. No less than 7 cases $(19 \%)$ died after a short follow-up, the average age at death being 27 for the 3 women, and 49 for the 4 men. There was great variation in the rate of progression and long asymptomatic periods were noted.

This tendency to insidious and symptomless advance in some cases is remarked by other authors, for example, Longcope and Winkenwerder (1933), already quoted. Kleeman, Hewitt, and Guze (1960) write that silent renal-destructive cases of pyelonephritis are clinically much less apparent than the recurrent pyelitis and cystitis group, in which even after many years renal functional impairment may be difficult to spot. Williams (1965) contrasted the two groups, those with recurrent acute symptoms and often no renal damage, seen by gynaecologists, and those with severe renal damage and intermittent asymptomatic pyuria, seen by physicians. Platt and Davson (1950) observed that uraemic changes may be extraordinarily chronic when renal failure from pyelonephritis is unaccompanied by hypertension, and that symptoms and signs of infection may be absent and the urine sterile when a case is at an advanced stage. Saphir and Taylor (1952) felt that this group was distinctive enough to be given? the name of Pyelonephritis Lenta, thereby stressing. the latency and chronicity of its course. In thei $\overrightarrow{5}$ : article the authors reserve this term for patients presenting with hypertension, but it is equally, if not more, applicable to the less common group of patients with slowly developing normotensive uraemia from pyelonephritis.

More selective surveys of children. Among $\overrightarrow{0}$ those published series in which it is possible to follow separately the progress of patients withw unobstructed urinary tracts, is the account of DeLuca, Fisher, and Swenson (1963) of 597 sucho infections in childhood, among whom 210 developed 'severe renal damage', and 11 underwent nephrecit tomy for unilateral pyelonephritis. Their articles does not contain enough detail to evaluate these remarkable and depressing figures. Smellie et al (1964) studied 200 unobstructed children and found half to have a radiographic abnormality.Malignant hypertension during the follow-up was observed in 3.

Persky (1965) described the follow-up of 160 children with urinary infection, the majority foro over 5 years. Among the 'primary pyelonephritis' group there were 3 deaths, and in each renap destructive changes were advanced when first seen and had not progressed to severe renal loss while under observation. The author speculated whethero the effects of dysplasia rather than the ravages of infection alone were responsible for such cases. $\overrightarrow{\overrightarrow{0}}$ This concept received early support from a paper by Porter and Giles (1956), and has been mentioned more recently by Crocker, Newton, and Harrison. (1965) and by R. Habib (1969, personal communication). Confusion with forms of hereditary neph ritis such as medullary cystic kidney may account for some such observations, and there is not much support for dysplasia as the basis for many cases.

Williams (1965) comments that 'in children with recurrent acute infection but without serious? obstruction we have often (sic) observed radio $\Rightarrow$ logically progressive loss of renal parenchyma ande. some are dead or in advanced renal failure'. Allen No (1965) dissented from the general view and con 7 sidered the evidence for chronic silent pyelonephritis not to be strong. Progressive renal destruction in ${ }^{\omega}$ children seemed to him more likely the result of repeated acute episodes of infection. Penn an£ Breidahl (1967), however, observed 9 out of 57, children with urinary infection and reflux to under-go progressive advance in $x$-ray renal damage even on chemotherapy. Progress was arbitrary in relation to infection; some progressed without 
observed reinfection, and some with repeated reinfection did not progress.

Mildenbergher, Fendel, and Marget (1966) calculated, after following up a random sample of about a quarter of the 824 children with nonobstructive pyelonephritis treated in hospital from $1932-62$, that $14 \%$ had died by 1964 , but threequarters of these died in the first year of life, which casts doubt on the validity of the group as unobstructive.

MacGregor and Freeman (1968), in a follow-up of 82 unobstructed children, considered that, 'there is a small group of children with reflux and serious renal damage that has been inflicted in early childhood; from these are drawn the examples of pyelonephritic renal failure which one encounters in later childhood and adolescence. Symptoms may be so scant as to be disregarded while renal destruction is taking place.'

Seventy-six children who had had non-obstructive urinary infection in hospital in 1940-49 were reinvestigated 15 to 25 years later by Lindblad and Ekengren (1969). There were no positive findings in the 18 males in the series. There had been progressive parenchymatous reduction of the kidneys by $x$-rays in 11 of the 58 women (19\%). Nevertheless, the results of tests of blood pressure, proteinuria, sedimentation rate, and creatinine clearance were not significantly different in those with $x$-ray changes from those without them. Unfortunately, no information is provided about the presence of reflux in these patients. P. Freeman (1969, personal communication) has found that 5 of a group of 128 non-obstructive children with infections showed evidence of increased renal scarring during a 4-year period, 4 without external evidence of infection. All were on continuous chemotherapy.

From all this sometimes contradictory reporting, a shadowy picture of the true course of events seems nevertheless to emerge. Continued urinary infection is likely to cause progressive $x$-ray deterioration in the kidneys, particularly, and perhaps solely, when reflux is there too. In most cases this is compatible with good health, and is not even recognizable by renal function studies at the time of completion of published surveys, which is, however, at the latest only in early middle life. A much smaller group exists of more malignant nature, 'pyelonephritis lenta', who proceed to death in uraemia, usually, but not always with hypertension, in adolescence or, at latest, in early middle life. Such cases are remarkable for their clinical silence, maintained until the terminal stages. The initial damage in most cases occurs very early, often in the preschool period, and though reflux is probably present in all, there is not yet an understanding of why some children are so gravely afflicted, among many who are involved. This is the group with which hereditary dysplasias, already discussed, are likely to be confused.

Pyelonephritis of pregnancy. We have already quoted observations to indicate that pyelonephritis of pregnancy and toxaemia of pregnancy are commoner in those women with a history of urinary infection in childhood, especially if they have pyelographic abnormalities. Woodruff and Everett (1954) estimate the incidence of pyelonephritis in general as about 1 in 350 pregnancies. Using the reverse approach, KincaidSmith et al. (1964) found the incidence of pyelographic abnormality in bacteriuric women to be as high as $45 \%$, and regarded pregnancy bacteriuria commonly as a manifestation of underlying chronic renal disease. Hanley (1965) considered acute-onchronic pyelonephritis in young women to be rather disastrous, and in a group of 88 women with acute pyelonephritis in pregnancy, mainly treated in hospital, $42 \%$ had serious renal damage 17 to 27 years later. Many had had trouble in childhood. Anong 164 women with bacteriuria of pregnancy, Gower et al. (1968) found $14 \%$ to have IVP abnormalities suggesting underlying disease from childhood. There was a still higher incidence in women who had had pyelonephritis in pregnancy. Reflux was not studied in these series, but Williams et al. (1968) observed this in $21 \%$ of a group of bacteriuric women, and Heidrick, Mattingly, and Amberg (1967) in 2.8\% of a group of 321 pregnant or post-partum women, one-third of whom had had pyelonephritis of pregnancy.

Sussman et al. (1969) consider that bacteriuria in pregnant women has usually followed overt infection in the past, and, by comparing a group of 88 bacteriuric with a similar group of non-bacteriuric pregnant women, confirmed that a past history of urinary infection is commoner among the former, and that $x$-ray abnormalities were present in $34 \%$ of bacteriurics compared with only $12 \%$ of controls.

It is not possible, then, to ascribe to pregnancy pyelitis a primary role in initiating pyelonephritic damage. Rather, it seems, does infection at that period reflect earlier trouble and, probably in many cases, increase resultant renal damage, in conformity with Gill and Hayslett's (1969) observation that pregnancy is deleterious to renal conditions in general.

Evidence from Necropsy Studies

Butler and Lanman (1937) found that the cause 
of death in $2 \%$ of 2043 necropsies in a children's hospital was directly due to pyelonephritis, contrasted with only 3 deaths from nephritis in the same period. $63 \%$ of deaths occurred under 2 years old, and the same proportion had malformations of the renal system. Almost identical results were reported by Spark et al. (1962) on the basis of 335 childhood necropsies. They noted the predominance of males in deaths under 2 years old. Neumann and Pryles (1962) studied 1999 necropsies in children under 16 over a 30 -year period from 1933. There were 31 cases of pyelonephritis among them $(1.5 \%)$ and $68 \%$ occurred under 2 years old, with a male preponderance. In the whole period there had only been 2 deaths from renal failure due to chronic pyelonephritis in this age-group. Burke (1965) surveyed necropsy records at the Mayo Clinic for $\mathbf{4 6}$ years and found that $2.7 \%$ of 3100 children had died of pyelonephritis, $40 \%$ under 1 year. North (1966) found $4 \%$ of pyelonephritis in 310 necropsies in children but there was a good reason, in the shape of malformation or a septicaemic type of terminal illness, for death in each case. He considered that there was no support from these studies for the genesis of adult chronic pyelonephritis in childhood. But perhaps it is not among childhood necropsies that one should look for traces of a process not to reach its culmination until a decade or two have passed, but rather in the patients still living.

There is a remarkable consistency in all these reports. The incidence of death from pyelonephritis in childhood is constant, occurs early, and is easily attributable to circumstances irrelevant to our survey. Only exceptionally in this age-group does chronic pyelonephritis come to necropsy.

In studies not confined to children, Black (1967) quotes necropsy figures for chronic pyelonephritis in Copenhagen from 1941 to 1946 , which give a mortality of $5.6 \%$ of 3607 necropsies, and in Prague from 1952 to 1954 of $6 \cdot 2 \%$ of 1196 necropsies. Kimmelstiel et al. (1961) using very strict criteria found 97 cases $(2 \cdot 8 \%)$ of chronic pyelonephritis among 3393 necropsies from 1954 to 1959. Only one case was aged less than 20. Focal pyelonephritic changes were observed in $2.4 \%$ of kidneys, and diffuse changes in the remaining $0.4 \%$. The sex ratio was 1 man to $1 \cdot 3$ women. KincaidSmith et al. (1958) ascribed at necropsy 25 out of 44 cases of malignant hypertension to pyelonephritis. It is interesting that only in $\mathbf{8}$ of these was there a history of chronic urinary infection. The age at death in males averaged 48 years, and in females 38 years, somewhat later than deaths from nephritis, particularly so in men.
A recent study of deaths in South Warwickshir covering the decade 1959 to 1968 inclusive has been: made for this review. Hospitals in this area serv $\overrightarrow{\vec{F}^{2}}$ a semi-rural population of about 200,000 people There were 7555 post-mortem examinations in the period, and $76(1 \%)$ of the deaths were primaril due to pyelonephritis. The sex incidence was equal, but if males with prostatic obstruction are excluded, the incidence was $2: 1$, with a female preponderance. In the same period there were 24 deaths from nephritis, with a male preponderance of $2: 1$ (Fig. 1). In the whole decade there wergu no deaths from pyelonephritis under 20 and only 4 (2 males) under 40 ! A rise in deaths among women aged between 40 and 60 was seen ( 8 deaths) while no significant number of male deaths occurred till after the age of 70 . The pattern for nephritit was different, with 5 deaths under the age of 30 and the remainder spread fairly evenly up to the age of 60 . Chronic pyelonephritis was frequent as a subsidiary diagnosis in older people, but as this condition has, as we have seen, little influence of general health until the terminal stages, it is doubtfu? if its presence will have done much to accelerat $\vec{E}$ the time of death.

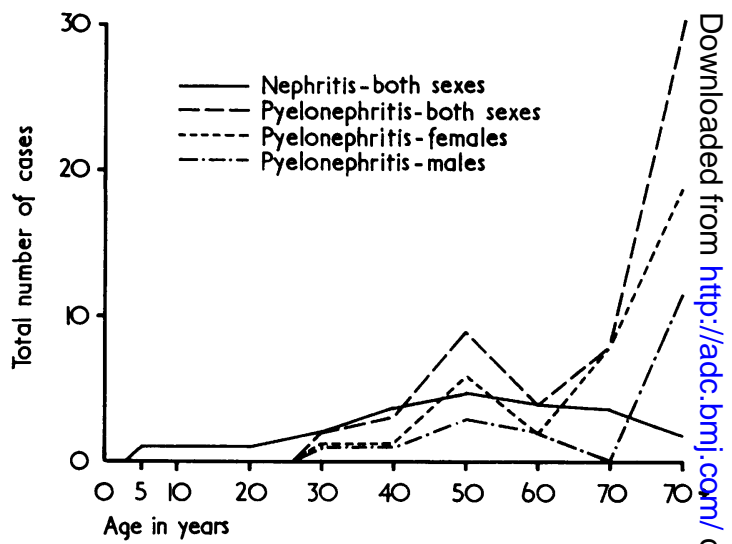

FIG. 1.-Number of deaths (by decades) from nephrit 옳 and from pyelonephritis in males (excluding prostatit obstruction) and females 1959-1968 (necropsy records 星. South Warwickshire Hospital Group).

The deaths of young people from chronio pyelonephritis in this part of Britain therefore are at the present time almost negligibly few. A few young people may have been transferred for dialysis to other hospitals, but this number is certainly very small and would affect nephritis more than pyelonephritis. It may be too that a few cases labelled as hypertensive deaths with nephros sclerosis were, in fact, pyelonephritic, but these to $\overrightarrow{8}$ were rare in the series. Though there was 
considerable number of stillbirths and neonatal deaths from uninfected congenital renal dysplasia or obstruction, it is interesting that there were no deaths in childhood from urinary infections during this 10 years. Chemotherapy in the past decade has enabled many children with severe renal malformations to limp forward through childhood with limited renal reserves, and will create a new group of fatalities in the second decade of life, unless renal transplantation becomes more freely available.

About 100 cases of urinary infection with reflux in children have been identified locally in the past 6 years, and it is probable that there are at least as many still undiagnosed in the child community. Nevertheless, it appears that only 10 women in the past decade have died under the age of 60 from chronic pyelonephritis. Unless the incidence of this disorder in childhood is increasing (and there is no reason to believe that this is so) the long-term ill-effects of childhood infection with reflux cannot be quantitatively very important.

The difference in the post-mortem incidence between these figures and those of Kimmelstiel et al. (1961), in the previous decade, may well be due, as Black (1967) declares, to the effects of earlier recognition coupled with modern treatment. Deaths from uraemia with pyelonephritis have, since 1959, become uncommon, he considers.

\section{Evidence from Statistical Sources}

The incidence of urinary infection in the general population of this country, if pyuria is taken as the diagnostic criterion, is estimated by Fuller (1966) at 27 patients per 1000 per annum, with a sevenfold preponderance of females. Kunin (1968) estimated that 1 in 10 American schoolgirls have had either bacteriuria or overt urinary infection by the age of 18. Sussman et al. (1969) found the incidence of bacteriuria to be $3.5 \%$ in women at every age from 20 to 65 . $90 \%$ of bacteriuric women had a history of urinary infection, and $34 \%$ of them had $x$-ray abnormalities in the urinary tract. Macaulay (1964), commenting on figures such as these, observes that they do not conform to a pool of female patients with unhealed renal infection whose numbers increase year by year. On the contrary as the sex incidence at necropsy from pyelonephritis, is approximately equal, the only explanation must be that most of the infections in girls eventually die out. Hodson (1965a), observing that focal renal scarring is uncommonly seen in $x$-ray departments after 45 , inquired whether such patients had died, become quiescent, or were no longer investigated. It is doubtful if the first or third of these explanations can be the right one. Clarke, Mielke, and
Leighton (1966), for example, studied the diagnoses of five million patients admitted to hospitals in the U.S.A. and Canada, and found that the incidence of hospital admissions for pyelonephritis and urinary tract infections remained numerically constant by decades from the ages 1 to 70 . The deaths from renal insufficiency at all ages, on the other hand, was only a small fraction of the figure for admissions in any 10-year age-group.

Hood, Falkheden, and Carlsson (1967), in an important paper from Goteberg, surveyed the deaths from renal diseases between 1950 and 1965 of all hospital patients from a population of 400,000 . $90 \%$ of them had come to necropsy. Dividing this 15-year period in half, they found that whereas deaths from chronic glomerulonephritis declined from $3 \cdot 1$ per 100,000 to $2 \cdot 7$ per 100,000 from the earlier to the later period, those from chronic nonobstructive pyelonephritis ( $42 \%$ of all renal deaths), rose from $3 \cdot 8$ per 100,000 to $7 \cdot 4$ per 100,000 in 1961 to 1965 . This rise was attributed to an increase in the abuse of analgesics, to which no less than $78 \%$ of patients in the later period admitted. As regards sexes, there were no deaths from nonobstructive pyelonephritis in males under 40 , very few among females under 30 , and the vast majority were among females aged 50 to 60 .

Gault and Dossetor (1966) observed that, though pyelonephritis was usually cited as a commoner cause of terminal renal failure than glomerulonephritis, with a ratio estimated variously at from $1 \cdot 5-5 \cdot 1$, nevertheless, glomerulonephritis emerged from statistics of renal transplants as the commonest cause of renal failure undergoing this procedure.

Several possible reasons for this are suggested, such as a bias towards males in transplant surgery, or the fact that in younger people terminal pyelonephritis is often complicated by anatomical or neurological defects, as well as a recent swing of the pendulum among nephrologists away from pyelonephritis as the probable reason for scarred failing kidneys of uncertain aetiology. Another cause Gault and Dossetor suggest may be a true fall in incidence of pyelonephritis of this severity, due to better management. But the explanation which seems to be most weighty is that most pyelonephritic deaths occur after the fifth decade which is the normal upper age limit for renal transplants.

This leads on finally to a consideration of the Registrar General's Statistical Reviews (1950 and 1967) (General Register Office, 1952, 1968). If deaths in the United Kingdom from 'pyelitis, pyelocystitis, and pyelonephritis' are compared with deaths from 'chronic nephritis' in 1950 and 1967, one observes (Fig. 2): 
(a) That the total deaths attributed to pyelonephritis have risen from 1000 in 1950, with an equal sex incidence, to 3000 in 1967, with a female preponderance of 2 to 1 .

(b) That the total deaths labelled as chronic nephritis have fallen from about $5 \frac{1}{2}$ thousand in 1950 (equal sexes) to $1 \frac{1}{2}$ thousand in 1967 (equal sexes).

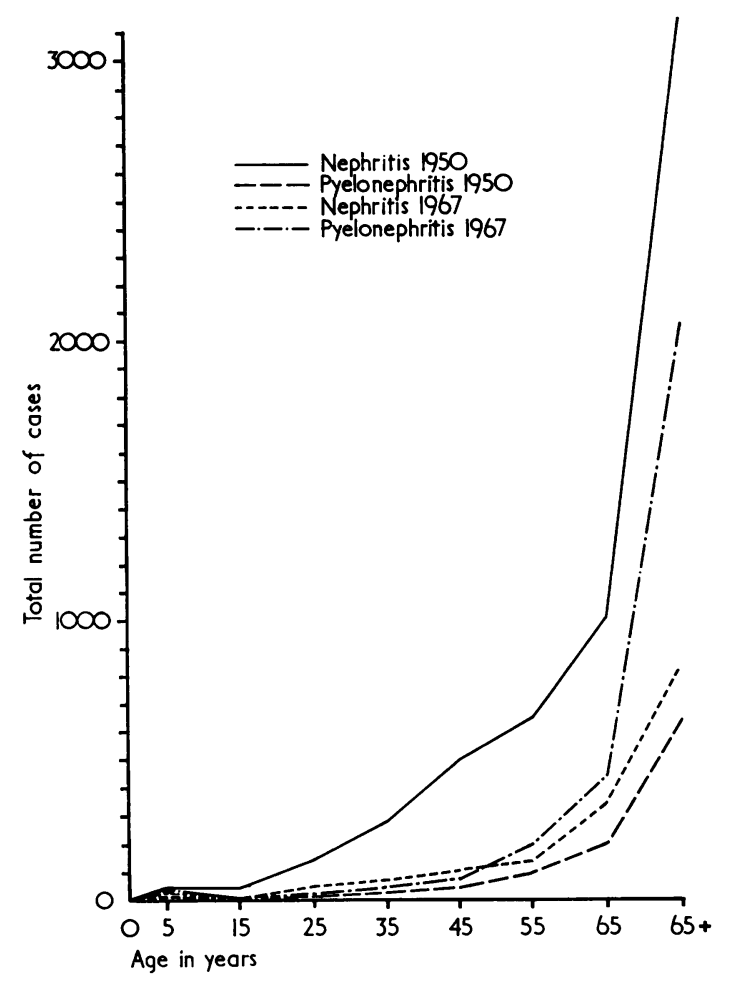

FIG. 2.-Total deaths (by decades) from nephritis and pyelonephritis, 1950 and 1967 (from Registrar General's Annual Statistical Reports for England and Wales).

These trends must in part be explained by a transfer of cases from the chronic nephritis to the pyelonephritis category, due to an increased belief by the medical profession in the latter condition as a cause of chronic interstitial nephritis.

(c) The female preponderance among deaths from pyelonephritis in 1967 is apparent in every age-group after the first decade (where the sex ratio is reversed), and becomes more striking with advancing age.

(d) The curve of increasing incidence of pyelonephritis through the decades of life begins to rise between 40 and 50 , rises steeply after 50 를. and precipitously after 60 .

(e) The general shape of the curve for chronic nephritis in 1967 is similar, with rather more deaths in the earlier adult decades. Between 40 and 50 , deaths from pyelonephritis out $-\frac{\bar{c}}{\bar{c}}$. number those from nephritis, but after this age the two curves rise steeply together.

(f) Total deaths from pyelonephritis between $10 \%$ and 40 years of age numbered only 146 in $1967^{\circ}$ ( $4.8 \%$ of total deaths from this cause), with $\dot{a}$ sex incidence of 2 women to 1 man.

Though not too much value must be given tow diagnoses based on death certification, certainn observations are valid, particularly so as theses figures correspond in a general way with what wei have learnt from the smaller local series based on necropsy reports. We can see that a small group of pyelonephritic patients dies in the earlier decades of adult life, examples no doubt of pyelonephritis? lenta, already severely damaged in childhood, whose early deaths could have been predicted if, in fact $\rightarrow$ renal damage had been identified. But it appears? that any impact on mortality from the much more $\overrightarrow{0}$ numerous cohort of girls with reflux and somes degree of focal renal scarring must be delayed at leasto until after middle life, and in the Registrar General's figures the parallel rise in deaths from chronic nephritis after that age (which is not seen in the necropsy studies that we have examined) confirmso that diagnostic confusions still exist between the two. Moreover, the continuation after the age of 40 of a sex difference in mortality unfavourable to women (absent in figures for chronic nephritis) indicates that there is some particular adverse influence in pyelonephritis which is confined tô women. Seeing that these patients have dieff of chronic and not of acute pyelonephritis, this influence must derive from earlier decades. Renah. complications of pregnancy, if not based upon pre-existing infection, are more likely to have been classified under chronic nephritis, but, as we have seen, many cases of toxaemia of pregnancy are, it any case, predisposed to by underlying pyelo nephritis. Fresh development of acute pyelo $N$ nephritis in young women which could lead tơ death from pyelonephritis, seems to be unusual, for as we have seen studies indicate that mosf examples of honeymoon and pregnancy pyelor nephritis are in fact recurrences of earlier infections?

The conclusion seems inescapable that it is upons urinary infection in youth that this late mortality in women should be blamed, and that this represents the sex-specific adverse influence stealthily operating against certain women throughout their later lives $\underset{\mathbb{D}}{\overparen{D}}$ 


\section{Implications for Treatment}

In this country the management of recurrent urinary infection in children accompanied by reflux has in the main been conservative, that is to say has employed long-term chemotherapy in preference to surgery. Edwards, Normand, and Smellie (1968) reported that reflux had disappeared in $40 \%$ of treated children after several years of continuous chemotherapy, and fresh scarring of the kidneys in children so treated was seldom seen. Hodson (1965b) observed contracted kidneys to resume growth when the urine was kept sterile. Claims for conservative treatment were also made by Pryles (1965) and by MacGregor and Freeman (1968). The very fact that so many urinary infections in childhood apparently die out later has been a powerful inducement to a watchful conservative attitude (Macaulay, 1964). However, as Bergström et al. (1968) point out, conclusive evidence of its long-term value cannot be obtained from uncontrolled studies such as these.

The study of Scott and Stansfeld (1968), in which 23 children who had had surgery for reflux were compared with 24 who had not, was limited by the fact that not all the unoperated cases were kept continuously on chemotherapy, lessening the force of the observation that in a three-year period the mean growth of the kidneys was greater in the operated group. In a recent paper, Scott (1969) found the success rate among his series of 87 children operated upon for reflux to be $97 \%$, and to be $90 \%$ among other published cases. Relapse of infection was still seen after operation in a quarter of cases, but the complication of post-operative ureteric obstruction was observed in only $4 \%$ of cases. Edwards et al. (1968) report a similar complication rate for children treated surgically and consider it too high for this to be the preferred method of treatment. Using long-term chemotherapy without surgery, P. Freeman (1969, personal communication) found a reinfection rate of $20 \%$ in a 4-year period.

One must be cautious in using impressive benefits of long-term therapy in children to justify the same regimen in adults (British Medical Journal, 1969). There is, in fact, no evidence that in adults it does have good effects. McGovern and Marshall (1969) are in no doubt that, in adults, surgical correction of reflux will often prevent progression of renal damage, while none of their cases was made worse by operation. Kern and Malament (1969), discussing reflux in adults, observe that, 'although the growing child may improve on conservative treatment, only one adult patient (out of 17 treated) has done well on this régime'.
This controversy cannot be settled, but there can be little doubt that if during childhood cases of reflux that would continue into adult life were recognizable, there would be a strong case for eliminating the reflux surgically at an early age. The value of long-term studies now in progress may not be so much to show conservative methods as the generally applicable best treatment, as to define those patients who are refractory to it, and who for their own protection in later life require surgery in childhood. Indeed, a recent paper (Rolleston, Shannon, and Utley, 1970) argues that infants with gross reflux should be operated upon forthwith, because the authors' considerable experience indicates that hydrostatic effects at this vulnerable age are at least as damaging as infection, and that progressive damage is confined to those with the most severe grade of reflux.

\section{Summary and Conclusions}

Necropsy study of the kidneys of adults suggests that progressive renal destruction of the type labelled as chronic pyelonephritis can progress irrespective of continuing bacterial infection. Whether or not infection has had some part in initiating the changes in a given kidney cannot be stated with absolute certainty, though the presence of papillary atrophy is a strong confirmatory point. Coarse focal scarring of the kidney indicates damage inflicted in childhood, whereas injury inflicted upon the adult kidney leads to a more general shrinkage, and is less capable of detection by the use of $x$-rays. Within the group of small generally contracted kidneys there are a number of newly recognized pathological entities, both hereditary and acquired, which can lead to uraemia in early life, and which, especially in males, have been wrongly regarded as the outcome of pyelonephritis.

Vesico-ureteric reflux can be incriminated as the almost invariable association with kidneys severely damaged by pyelonephritis. This is particularly well documented in children, but as it is being more sought for among adults, it is being found there too. The condition is in most cases congenital, with a tendency in many cases to a natural cessation with increasing age, and it seems also sometimes to cease when pyelonephritic scarring has become severe. It is the combination of reflux with infection that is damaging, and there seems to be a special vulnerability to these ill-effects for kidneys of children under 5 years old.

Many follow-up studies are so unselective as to be confusing, but it is clear that fatal infections in childhood are now largely restricted to a group of 
boys with obstructive congenital malformations, and these occur within the first 2 years of life. Infection in the neonatal period has a different and better prognosis if not part of a septicaemic illness, because malformed kidneys or cases with reflux seldom become infected so soon after birth. During subsequent childhood and early adult life the great majority of young people with recurrent urinary infection remain in good health apart from their recurrences, though possessed in many cases of pyelographic abnormality. Hypertension, or decrease in renal function, is seen only occasionally. There is, however, a small group with a malignant course, who die in adolescence or more commonly in early adult life of 'pyelonephritis lenta', a very insidious form of renal failure with or without hypertension, often unattended by symptoms of ill health until the terminal stages. Many of these patients are women, and indirect evidence supports the hypothesis that they represent the end result of destructive renal infection, often clinically silent, associated with vesico-ureteric reflux in very early childhood. These patients do not seem to owe their relentless decline to repeated re-infection. Numerically this is a small group.

In some of the remainder with recurrent infection, who are the great majority, progressive $x$-ray deterioration can be seen in the kidneys over many years, particularly and perhaps solely when reflux is present. At the age when published surveys end, this damage was not recognizable by renal function studies in most cases, so one needs to look elsewhere for the final outcome in these patients. Pyelonephritis of pregnancy cannot be implicated as a first cause of much renal damage, for all the evidence suggests that it is usually pre-existing renal damage that comes to light at this time. Pregnancy infection can, however, seriously aggravate this damage.

Necropsy studies confirm that the mortality from pyelonephritis in childhood is constant, and occurs early and from causes without relevance to later life. Deaths from chronic pyelonephritis in childhood are exceptional, and indeed are very few under the age of 40. Deaths among women from this cause begin to rise after 40 , and more notably after 50 , but the precipitous rise in mortality that is seen in the elderly in both sexes does not occur until after 60. Even at this age women still preponderate by 2 to 1 , if prostatic cases are excluded. Other statistical surveys lead to the conclusion that an adverse influence becoming steadily more obvious with advancing age is operating upon women to cause a large and disproportionate number of deaths from chronic pyelonephritis in the female sex between 50 and 70 years of age. The necessary deduction seems to be that it is not until this epoch of women's lives that we witness the final impact of renal damage inflicted by urinary infection in child-o hood, another condition in which we observe the음 same disproportionate female liability.

The risk to young women of death or invalidism $\frac{\varnothing}{\varrho}$ following urinary infection in childhood is commonly exaggerated. This risk is less a statistical anxiety ${ }_{3}^{\infty}$ than a series of individual tragedies, numerically? small, but the more devastating in that they occur $\vec{\omega}$ in the creative period of life. In the great majority of girls the tendency to urinary infection seems to die out slowly, with no permanent ill effect on? health at any age, and resulting at most in thecr incidental finding of unilateral loss of renal substance after death from some other cause. But not all. escape so lightly, and there is a significant fraction $\overrightarrow{0}$ of female deaths in late middle age directly attribu- 0 table to early pyelonephritic experiences. Some 20 years it seems may be lopped off many women's lives by this childhood scourge.

Could this number be reduced by surgically correcting persistent reflux at the end of childhood ? There is a little evidence, but no proof, that this. might be true, and controlled studies are needed. As regards the tragic few who succumb to pyelonephritis lenta, prevention depends on their detection in infancy. Because the reason for the specialo vulnerability of these patients is unknown, the $\frac{\mathbb{Q}}{2}$ question whether treatment given early would be $\underset{\overrightarrow{2}}{\stackrel{2}{*}}$ protective is still unanswerable, but the essentialo first step must be to identify them by improved screening techniques directed at the infant and toddler age-groups.

\section{REFERENCES}

Allen, T. D. (1965). Pathogenesis of urinary-tract infections in children. New England Fournal of Medicine, 273, 1421.

Angell, M. E., Relman, A. S., and Robbins, S. L. (1968). 'Active'음 chronic pyelonephritis without evidence of bacterial infection. New England Fournal of Medicine, 278, 1303.

Ashken, M. H. (1967). A study of the renal vascular patterns in hypertension, chronic pyelonephritis and other diseases. Annals of the Royal College of Surgeons of England, 40, 82. Baker, R., Maxted, W., Maylath, J., and Shuman, I. (1966). Relation of age, sex and infection to reflux. Fournal of Urology, 95, N 27.

Bengtsson, U., Lincoln, K., and Hood, B. (1967). Long-termw antibacterial treatment of chronic pyelonephritis. Acta Medica攵 Scandinavica, 181, 641.

Bergström, T., Lincoln, K., Redin, B., and Winberg, J. (1968)을 Studies of urinary tract infections in infancy and childhood Acta Paediatrica Scandinavica, 57, 186.

Black, D. A. K. (1966). The problem of chronic pyelonephritis: Practitioner, 197, 593.

(1967). Renal Disease. 2nd ed., p. 350. Blackwell, Oxford. $\overline{0}$

Blight, E. M., Jr., and O'Shaugnessy, E. J. (1969). Vesicouretera. $\vec{D}$ reflux in children: a prospective study. Fournal of Urology $\frac{\text { P }}{2}$ $102,44$. 
Brentjens, J. R. H., Vreeken, J., Feltkamp-Vroom, T., and Helder, A. W. (1968). Pyelonephritis-like lesions as a late effect of diffuse intravascular coagulation. Acta Medica Scandinavica, 183, 203.

British Medical fournal (1969). Leading article. Chronic bacteriuria. 1, 661 .

Bruezière, J. (1965). Le reflux vésico-urétéral chez l'enfant et le nourisson. Fournal d'Urologie et de Néphrologie, 71, 141.

Burke, E. C. (1965). Commentary on urinary tract infections in children. Mayo Clinic Proceedings, 40, 113.

Butler, A. M., and Lanman, T. H. (1937). Examination of the child with chronic pyelonephritis. New England fournal of Medicine, 217, 725.

Clarke, B. G., Mielke, R., and Leighton, E. (1966). Urology in hospitals of the United States and Canada, 1963 and 1964 fournal of Urology, 96, 417.

Crocker, D. W., Newton, K. A., and Harrison, J. H. (1965). Results of surgical management of unilateral pyelonephritis with hypertension. American fournal of Surgery, 110, 405.

DeLuca, F. G., Fisher, J. H., and Swenson, O. (1963). Review of recurrent urinary-tract infections in infancy and early childhood. New England fournal of Medicine, 268, 75.

De Wardener, H. E. (1965). The difficulty of diagnosing pyelonephritis. British fournal of Urology, 37, 1 .

Edwards, D., Normand, I. C. S., and Smellie, J. M. (1968). Vesicoureteric reflux. Lancet, 1, 1376.

Emmett, J. L., Alvarez-Ierena, J. J., and McDonald, J. R. (1952). Atrophic pyelonephritis versus congenital renal hypoplasia. fournal of the American Medical Association, 148, 1470.

Freedman, L. R. (1967). Chronic pyelonephritis at autopsy. Annals of Internal Medicine, 66, 697.

Fuller, J. C. (1966). Urinary infections. Fournal of the College of General Practitioners, 11, 294.

Gault, M. H., and Dossetor, J. B. (1966). Chronic pyelonephritis: relative incidence in transplant recipients. New England fournal of Medicine, 275, 813.

General Register Office (1952 and 1968). Registrar General's Statistical Review for England and W'ales for 1950 (and 1967). Part I, Tables, Medical. H.M.S.O., London.

Gianantonio, C. A., Vitacco, M., Mendilaharzu, F., and Gallo, G. (1968). The hemolytic-uremic syndrome: renal status of 76 patients at long-term follow-up. Fournal of Pediatrics, 72, 757

Gill, G. N., and Hayslett, J. P. (1969). Hereditary nephritis and pregnancy. American fournal of Obstetrics and Gynecology, $104,19$.

Gower, P. E., Haswell, B., Sidaway, M. E., and de Wardener, H. E. (1968). Follow-up of 164 patients with bacteriuria of pregnancy. Lancet, 1, 990.

Halverstadt, D. B., Leadbetter, G. W., Jr., and Field, R. A. (1966). Pyelonephritis in the diabetic; correlation of open renal biopsies and bacteriologic studies. Fournal of the American Medical Association, 195, 827.

Hanley, H. G. (1964). Pyelonephritis and ascending infection from the lower urinary tract. Fournal of Urology, 91, 1 .

(1965). Pyelonephritis of pregnancy. British fournal of Urology, 37, 53.

Heidrick, W. P., Mattingly, R. F., and Amberg, J. R. (1967). Vesicoureteral reflux in pregnancy. Obstetrics and Gynecology, 29, 571 .

Hickler, R. B., Birbari, A. E., Howard, F. H., Crocker, D. W., Lauler, D. P., Harrison, J. H., Crane, C., and Vagnucci, A. I. (1965). A comparison of unilateral pyelonephritis and renal artery stenosis associated with hypertension. American fournal of Surgery, 109, 715.

Hinman, F., Jr., and Miller, E. R. (1964). Mural tension in vesical disorders and ureteral reflux. Fournal of Urology, 91, 33

Hodson, C. J. (1965a). Coarse pyelonephritic scarring or 'atrophic pyelonephritis'. Proceedings of the Royal Society of Medicine, 58, 785.

(1965b). The radiology of chronic pyelonephritis. Postgraduate Medical fournal, 41, 477.

and Wilson, S. (1965). Natural history of pyelonephritic scarring. British Medical fournal, 2, 191.

Hood, B., Falkheden, T., and Carlsson, M. (1967). Trends and present pattern of mortality in chronic uremia. Acta Medica Scandinavica, 181, 561.

Hutch, J. A., Ayres, R. D., and Noll, L. E. (1967). Vesico-ureteral reflux. Lancet, $1,218$.
Kanasawa, M., Moller, J., Good, R. A., and Vernier, R. L. (1965). Dwarfed kidneys in children. American fournal of Diseases of Children, 109, 130.

Kase, S. (1965). Eighteen years of ureterovesical obstruction with hydronephrosis and megaloureter in a solitary kidney. Fournal of Urology, 94, 327.

Kern, H. B.. and Malament, M. (1969). Vesico-ureteral reflux and the adult male. British fournal of Urology, 41, 295.

Kimmelstiel, P., Kim, O. J., Beres, J. A., and Wellmann, K. (1961) Chronic pyelonephritis. American fournal of Medicine, 30, 589.

Kincaid-Smith, P., Bullen, M., Mills, J., Fussen, U., Huston, N., and Goon, F. (1964). The reliability of screening tests for bacteriuria in pregnancy. Lancet, 2, 61 .

-, McMichael, J., and Murphy, E. A. (1958). The clinical course and pathology of hypertension with papilloedema (malignant hypertension). Quarterly fournal of Medicine, 27, 117.

Kleeman, C. R., Hewitt, W. L., and Guze, L. B. (1960). Pyelonephritis. Medicine, $39,3$.

Klotz, P. G. (1969). Ureteral reflux in adults. Canadian Medical Association fournal, $100,4$.

Kunin, C. M. (1968). Emergence of bacteriuria, proteinuria and symptomatic urinary tract infections among a population of schoolgirls followed for 7 years. Pediatrics, 41, 968.

Laplane, R., and Etienne, M. (1968). L'infection urinaire néonatale: à propos de 34 observations personelles. Archives Française de Pédiatrie, 25, 1059.

Lindblad, B. S., and Ekengren, K. (1969). The long term prognosis of non-obstructive urinary tract infection in infancy and childhood after the advent of sulphonamides. Acta Paediatrica Scandinavica, 58, 25.

Little, P. J., McPherson, D. R., and De Wardener, H. E. (1965). The appearance of the intravenous pyelogram during and after acute pyelonephritis. Lancet, 1, 1186.

Lloyd Still, J., and Cottom, D. (1967). Severe hypertension in childhood. Archives of Disease in Childhood, 42, 34.

Longcope, W. T., and Winkenwerder, W. L. (1933). Clinical features of the contracted kidney due to pyelonephritis. Bulletin of the fohns Hopkins Hospital, 53, 255.

Macaulay, D. (1964). Recurrent urinary infection in girls. The case for conservative management. Lancet, 2, 1319.

McGovern, J. H., and Marshall, V. F. (1969). Reflux and pyelonephritis in 35 adults. Fournal of Urology, 101, 668 .

MacGregor, M. E., and Freeman, P. (1968). Subclassification of childhood urinary tract infections as an aid to prognosis. In Urinary tract infection, p. 95 . Ed. by F. O'Grady and W. Brumfitt. Oxford University Press, London.

Meadow, S. R., White, R. H. R., and Johnston, N. M. (1969). Prevalence of symptomless urinary tract disease in Birmingham schoolchildren. 1-Pyuria and bacteriuria. British Medical fournal, 3, 81 .

Mildenbergher, H., Fendel, H., and Marget, W. (1966). Das Spätschicksal der Kinder mit Harnwegsinfektionen. Deutsche Medizinische Wochenschrift, 91, 1293.

Mongeau, J. G., and Worthen, H. G. (1967). Nephronophthisis and medullary cystic disease. American fournal of Medicine, 43, 345.

Murdoch, J. McC., Geddes, A. M., Tulloch, W. S., Newsam, J. E., Thompson, W. N., Bidwell, D., and Wallace, E. T. (1966). The problem of pyelonephritis. Practitioner, 196, 800 .

Neumann, C. G., and Pryles, C. V. (1962). Pyelonephritis in infants and children. American fournal of Diseases of Children, $104,215$.

North, A. F., Jr. (1966). Pyelonephritis in children: an autopsy study. Fournal of Urology, 95, 622.

Penn, I. A., and Breidahl, P. D. (1967). Ureteric reflux and renal damage. Australian and New Zealand fournal of Surgery, 37. 163.

Perkoff, G. T. (1967). The hereditary renal diseases. New England Fournal of Medicine, 277, 79.

Persky, L. (1965). Pyelonephritis in children. ournal of Urology, 94, 20.

Platt, R., and Davson, J. (1950). A clinical and pathological study of renal diseases. II. Diseases other than nephritis. Quarterly fournal of Medicine, 19, 33.

Porter, K. A., and Giles, H. McC. (1956). A pathological study of five cases of pyelonephritis in the newborn. Archives of Disease in Childhood, 31, 303. 
Pryles. C. V. (1965). Progress in Pyelonephritis. p. 735. Davis, Philadelphia.

Relman, A. S. (1966). Comment (on chronic pyelonephritis). In Controversy in Internal Medicine, p. 328. Ed. by F. J. Ingelfinger, A. S. Relman, and $M$. Finland. Saunders, Philadelphia.

Rolleston, G. L., Shannon, F. T., and Utley, W. L. F. (1970). Relationship of infantile vesico-ureteric reflux to renal damage. British Medical fournal, 1, 460.

Rosenheim, M. L. (1963). Problems of chronic pyelonephritis. British Medical fournal, $1,1433$.

Saphir, O., and Taylor, B. (1952). Pyelonephritis lenta. Annals of Internal Medicine, 36, 1017.

Savage, D. C. L., Wilson, M. I., Ross, E. M., and Fee, W. M. (1969). Asymptomatic bacteriuria in girl entrants to Dundee primary schools. British Medical fournal, 3, 75.

Scott, J. B. S. (1969). Results of anti-reflux surgery. Lancet, 2, 68.

—, and Stansfeld, J. M. (1968). Treatment of vesico-ureteric reflux in children. Archives of Disease in Childhood, 43, 323.

Smallpeice, V. (1968). Urinary Tract Infection in Childhood and Its Relevance to Disease in Adult Life. Heinemann, London.

Smellie, J. M. (1966). Medical aspects of urinary infection in children. fournal of the Royal College of Physicians of London, $1,189$.

- Hodson, C. J., Edwards, D., and Normand, I. C. S. (1964). Clinical and radiological features of urinary tract infections in children. British Medical fournal, $2,1222$.

-, and Normand, I. C. S. (1966). Clinical features and significance of urinary tract infection in children. Proceedings of the Royal Society of Medicine, 59, 415.

Smith, J. F. (1962). The diagnosis of the scars of chronic pyelonephritis. Fournal of Clinical Pathology, 15, 522.

Spark, H., Travis, L. B., Dodge, W. F., Daeschner, C. W., Jr., and Hopps, H. C. (1962). Prevalence of pyelonephritis in children at autopsy. Pediatrics, 30, 737.

Spence, H. M., Murphy, J. J., McGovern, J. H., Hendren, W. H., and Pryles, C. V. (1964). Urinary tract infections in infant and children. Fournal of Urology, 91, 623.

Spicer, R. D., Ogg, C. S., Saxton, H. M., and Cameron, J. S. (1969): Renal medullary cystic disease. British Medical fournal, 159 824.

Stamey, T. A., Govan, D. E., and Palmer, J. M. (1965). The localization and treatment of urinary tract infections: the rolD of bactericidal urine levels as opposed to serum levels $\bar{p}$. Medicine, 44, 1.

Stansfeld, J. M. (1966). Relapses of urinary-tract infections in children. British Medical fournal, 1, 635.

Steele, R. E., Jr., Leadbetter, G. W., Jr., and Crawford, J. DW (1963). Prognosis of childhood urinary-tract infection: New England fournal of Medicine, 269, 883.

Sussman, M., Asscher, A. W., Waters, W. E., Evans, J. A. S. $\overrightarrow{2}$ Campbell, H., Evans, K. T., and Williams, J. E. (1969)ev Asymptomatic significant bacteriuria in non-pregnant womene I. Description of a population. British Medical fournal, 1, 7990

Turner-Warwick, R. T. (1962). Ureteric reflux: the clinicat problem and investigation. Proceedings of the Royal Society of Medicine, 55, 419.

Weiss, S., and Parker, F., Jr. (1939). Pyelonephritis: its relation to vascular lesions and to arterial hypertension. Medicine, $18 f$ 221.

Whalen, R. E., and McIntosh, H. D. (1962). The spectrum of hereditary renal diseases. American fournal of Medicine, 33, 2820

Wharton, L. R., Gray, L. A., and Guild, H. G. (1937). The late effects of acute pyelitis in girls. Fournal of the American Medical Association, 109, 1597.

Williams, D. I. (1965). Pyelonephritis and reflux. Proceeding $D$ of the Royal Society of Medicine, 58, 1038.

Williams, G. L., Davies, D. K. L., Evans, K. T., and Williams, J. E. (1968). Vesicoureteric reflux in patients with bacteriuria in pregnancy. Lancet, $2,1202$.

Woodruff, J. D., and Everett, H. S. (1954). Prognosis in childhood urinary infections in girls. American fournal of Obstetrics and Gynecology, 68, 798. 